NBER Working Paper Series

\title{
INTEREST RATE RISK AND THE REGULATION \\ OF FINANCIAL INSTITUTIONS
}

Jay B. Morrison* and David H. Pyle**

Working Paper No. 266

National Bureau of Economic Research, Inc.

204 Junipero Serra Boulevard, Stanford, CA 94305

July 1978

This paper has not undergone the review accorded official NBER publications; in particular, it has not been submitted for approval by the Board of Directors.

This research was supported by a grant to NBER from NSF-RANN (Grant No. APR76-02511). The views expressed herein do not necessarily reflect those of the National Science Foundation. The authors are indebted to George Kaufman, Sherman Maisel, J. Huston McCulloch, Barr Rosenberg, and William Sharpe for comments on earlier drafts.

*Wells Fargo Bank, San Francisco.

** University of California, Berkeley. 
INTEREST RATE RISK AND THE REGULATION OF FINANCIAL INSTITUTIONS

Jay B. Morrison and David H. Pyle

\begin{abstract}
A bank or other financlal institution is potentially subject to at least four types of risk: (1) Credit risk--defaults or delays in repayments. (2) Fraud--embezzlement or insider abuse. (3) Liquidity risk--or high cost of obtaining needed cash. (4) Interest rate risk--differential changes in the value of assets and liabilities as interest rates shift. This paper reports a study of the interest-rate elasticity of the net worth of a commercial bank. Most of the study is devoted to the development of the necessary methodology to measure the interest-rate elasticity (IRE) of a bank's asset/liability mix.

The report is organized into four major sections. The first summarizes the history of interest-rate elasticity models and points out the problems in applying them to bank assets and liabllitles. An analytical framework is then developed to calculate the IRE of a portfolto of assets and liabilities.

The next three sections apply the framework to a simulated bank. For simplicity, the bank is assumed to have only two classes of assets (commerclal loans and cash) and three classes of liabilities (demand deposits, large denomination CD's, and capital). The second section develops models of the cash flows associated with each of the assets and liabilities. The third section quantifles the parameters necessary to calculate the net worth and IRE measures, and the fourth section details the design of a simulation and some simulation results for the 1973-75 period.

The report concludes with a discussion of the regulatory implications of the study.
\end{abstract}

Jay B. Morrison Investment Division Wells Fargo Bank P.0. Box 44025 San Francisco, CA 94111 415/396-2828 


\title{
INTEREST RATE RISK AND THE REGULATION OF FINANCIAL INSTITUTIONS
}

\author{
Jay B. Morrison and David H. Pyle
}

In this study we are concerned with the market value of net worth in a financial institution. The financial institution is presumed to hold assets and to issue deposits with the difference in market values of assets and deposits being the net worth of the institution. This study considers the effects on net worth of changes in the level and structure of defaultfree interest rates. As net worth approaches zero, depositors have no buffer between the value of their deposits and fluctuations in asset values. Also, regulators must know the potential for a given institution's net worth falling to zero or below before the subsequent examination. This suggests that a forecast of the proportional change in net worth over a given time period is an important aspect of the examination process.

There are many sources of potential change in the net worth of a financial institution over any time period, including such important factors as default risk and the chance that the institution's employees may prove to be dishonest or incompetent. An implication of this study is that regulator's concern regarding factors such as credit risk and managerial competence may be more finely focused if the effects of interest rate risk on net worth have been quantified.

To this end, we shall begin by describing the basic model of interest rate elasticity for fixed income securities. A discussion of the problems of adapting this model to the portfolio of a financial institution will follow. The next sections describe the results of a simulation of the interest rate elasticity model for a wholesale bank. ${ }^{1}$ An important aspect

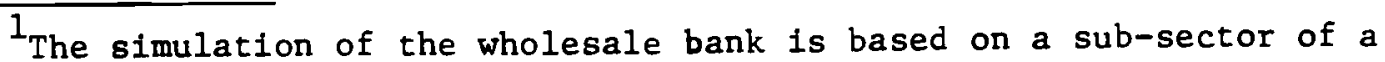
particular bank. The assets of this sub-sector are cash and commercial loans and the liabilities are demand deposits, purchased funds (which can also be thought of as the net position in securities), and equity capital. 
of this simulation is the attempt to account for the full cash flow effects of changes in the level and structure of default-free interest rates. For example, the effects of interest rates on cash flows due to loan commitments are explicitly modeled. The final section contains our concluding remarks.

Interest Rate Elasticity for Bonds

It was Macaulay (1938) who first defined the concept of duration to measure the time dimension of a bond. If we let:

$$
\begin{aligned}
& s_{1}, \cdots, s_{t} \text { be payments received at times } 1, \cdots, t ; \\
& P_{1}, \cdots, P_{t} \text { be the present value at time } 0 \text { of those payments; }
\end{aligned}
$$

then the duration (D) of the payment stream is defined as:

$$
D=\frac{\sum_{i=1}^{t} P_{i}^{i}}{\sum_{i=1}^{t} P_{i}}
$$

In this view, the duration is a weighted average of the payment dates, with the weight for period $i$ equal to the proportional contribution to the present value made by $\mathrm{S}_{i}$.

Macaulay interpreted duration as the period of time that elapses before the average dollar of present value is received. Under this interpretation, he argued for the use of duration as a measure of how long a dollar invested in a bond remained invested, and noted several advantages in the use of duration rather than maturity. Hicks (1939) defined an "average period" of a payment stream that is equivalent to Macaulay's duration. Hicks, however, interpreted and used the measure as "an elastic1ty [of capital value] with respect to a discount ratio." It may therefore 
be useful to think of duration as a measure of an investment's interestrate elasticity which has a time dimension and interpretation.

\section{A model of interest rate changes}

To see that duration does have an elasticity interpretation, it is useful to specify a model for interest-rate changes. First, denote the one-period interest rate expected to obtain during the period beginning at time t-1 by $r_{t}$. Under the expectations hypothesis with no liquidity premium, the t-period spot rate would then be the geometric mean of the product of $1+$ the current one-period spot rate and $1+$ each of the F-1 oneperiod forward rates. If $\left(1+R_{t}\right)^{-t}$ denotes the $t$-period discount factor, then:

$$
1+R_{t}=\left[\sum_{i=1}^{t}\left(1+r_{1}\right)\right]^{1 / t} .
$$

To simplify the notation, let $r_{F t}=1+r_{t}$ and $R_{F t}=\left(1+R_{t}\right)^{t}$. Using this notation, the present value of the certain payment stream, $s_{1}, \cdots, s_{t}$, can be written as:

$$
P V_{s}=\sum_{i=1}^{t} \frac{s_{i}}{R_{F i}} .
$$

Now, assume that shifts in interest rates can be described by some multiplicative function $f(h, t)$, such that:

$$
\begin{aligned}
& R_{F t}=\hat{R}_{F t} \cdot f(h, t) \\
& \frac{\partial R_{F t}}{\partial h}=\hat{R}_{F t} \frac{\partial f(h, t)}{\partial h}
\end{aligned}
$$


where $h=r_{F l}=1$ plus the first period spot rate. This assumption allows (3) to be rewritten as:

$$
P V_{s}=\sum_{i=1}^{t} \frac{s_{i}}{f(h, i) \hat{R}_{F i}}
$$

Interest rate elasticity with equal proportional effects on all one-period rates

This formulation provides a tractable means of expressing rate changes, which allows for the possibility that some of the one-period rates change more than others. For this example, however, it will be assumed that all one-period rates (spot and forward) change by the same proportional amount, which can be modeled with a shift function of the form,

$$
f(h, t)=h^{t}
$$

This means that when shifts in the discount function occur, they do so in such a way that the entire function is shifted up or down without distortion. Under this specification, we can study the effect of rate shifts on the present value of the stream $s_{1}, \cdots, s_{t}$. Using (4), we can express the present value as:

$$
P V_{s}=\sum_{i=1}^{t} s_{i} \delta_{i},
$$

where

$$
\delta_{i}=\frac{1}{h^{i} \hat{R}_{F i}}
$$

Taking the differential, we get: 


$$
\mathrm{dPV}_{s}=-\sum_{i=1}^{t} \frac{\mathrm{S}_{i} \delta_{i}{ }^{i}}{h} \mathrm{dh}
$$

and dividing by PV gives:

$$
\frac{d P V_{s}}{P V_{s}}=-\left[\frac{\sum_{i=1}^{t}\left(S_{i} \delta_{i}\right) i}{\sum_{i=1}^{t} S_{i} \delta_{i}}\right] \cdot \frac{d h}{h} .
$$

By noting that $\mathrm{S}_{i} \delta_{i}$ is equal to $\mathrm{P}_{i}$, the present value of the bond payment $\mathrm{S}_{i}$, it is clear that the term in brackets in equation (5) is, in fact, Macaulay's duration. Since $\mathrm{dPV}_{s} / P V_{s}$ is the percentage change in present value, and $\mathrm{dh} / \mathrm{h}$ is the percentage change in the discount factor, the ratio $-\sum_{i=1}^{t}\left(s_{i} \delta_{i}\right) i / \sum_{i=1}^{t} S_{i} \delta_{i}$ is the interest-rate elasticity of net worth. It is important to note that duration and interest rate elasticity (IRE) will be equivalent only for this particular specification of $f(h, t)$, i.e., one in which unanticipated rate movements shift the entire yield curve up or down by proportionately identical moments.

\section{Interest rate elasticity with decreasing effects on forward rates}

The relationship for interest rate elasticity established by Macaulay is simple and appealing. However, the interest rate change process which underlies it is not very realistic. Observers of the behavior of defaultfree interest rates suggest that a preferable model is one in which the change in rates is largest for the near term one-period rates and smaller for later one-period rates (see Hodges (1975) and Yawitz, Hempel, and Marshal1 (1975)). 
An alternative specification for the interest rate shift function is

$$
f(h, t)=h^{t^{\alpha}} \quad 0<\alpha \leqq 1
$$

With this shift function, we can derive the following relationship

$$
\frac{d P V_{s}}{P V_{s}}=-\left[\frac{\sum_{i=1}^{t}\left(s_{i} \delta_{i}\right) i^{\alpha}}{\sum_{i=1}^{t} s_{i} \delta_{i}}\right] \cdot \frac{d h}{h}
$$

where the term in brackets is the interest rate elasticity (IRE). Comparing equations (5) and ( $\left.5^{\prime}\right)$, it is clear that Macaulay's duration is the upper limit $(\alpha=1)$ on the interest rate elasticity of bond value for the more general shift function.

Using equation ( $\left.5^{\prime}\right)$, we can then generate the values of IRE as a function of $\alpha$ for two hypothetical three-period loans, one with equal cash flows in each period, and the other a $10 \%$ coupon bond paying three coupons and repaying the face value. The example in Table 1 is for a particular structure of default-free interest rates but the qualitative effect of decreasing $\alpha$ would be the same for any structure of rates.

Table 1. Interest Rate Elasticity (IRE) from Equation (5') for 3 Period Debts when $\delta_{1}=0.9, \delta_{2}=0.8$, and

\begin{tabular}{|c|c|c|}
\hline$\alpha$ & $\begin{array}{c}\text { IRE } \\
\text { Equal Payment Loan }\end{array}$ & $\begin{array}{c}\text { IRE } \\
10 \% \text { Coupon Bond } \\
\end{array}$ \\
\hline 1 & -2.11 & -2.74 \\
\hline .75 & -1.76 & -2.12 \\
\hline .5 & -1.48 & -1.64 \\
\hline .25 & -1.26 & -1.28 \\
\hline
\end{tabular}
$\delta_{3}=0.75$ 
The effect of a decreasing impact on forward rates becomes apparent in

Table 1. For example, if there is no attenuation (i.e., $\alpha=1$ ), a $1 \%$

increase in one plus the first, second, and third period default-free rates (which is a 110 basis point increase for a $10 \%$ spot or forward rate) would produce a $2.74 \%$ decrease in the value of the hypothetical $10 \%$ bond. For $\alpha=.75$, a $1 \%$ increase in one plus the one-period rate would result in an increase of about $.7 \%$ in one plus the second period rate, and an increase of about $.6 \%$ in one plus the third period rate. This level of attenuation In the interest rate change results in the decrease in value of the $10 \%$ bond being $2.12 \%$. In other words, the loss of value for $\alpha=.75$ is about $77 \%$ of the loss of value for $\alpha=1$. Similarly for the equal payment loan, the loss of value of the loan resulting from a $1 \%$ increase in one plus the first period rate is about $17 \%$ less if $\alpha=.75$ rather than 1 .

\section{An empirical model of interest rate changes}

The example in the preceding section of this paper serves to illustrate the effect on IRE of interest rate changes which diminish as one considers forward rates for times ever more distant from the present. This model is purely hypothetical. For the analysis of the IRE for bonds, we need an empirically estimated model of the process by which default-free rates change.

Details of the model of interest rate changes which is used in the simulations reported later in this study may be found in Morrison (1977). Morrison developed a testable model of changes in the term structure of default-free interest rates from a stochastic model of the term structure by Vasicek (1976). Fundamental assumptions in the Vasicek model are (1) the spot rate follows a continuous Markov process, (2) the price of a discount bond maturing at time $s$ is determined by the anticipated spot 
rate process from the present until time $s$, and (3) the bond market is efficient. For our purposes, the importance (and perhaps the limitation) of these assumptions is revealed by their implication that the value of the spot rate is the only state variable determining the term structure of interest rates.

For empirical estimation, Morrison used Vasicek's term structure equation to derive the effect of changes in the spot rate on yields to maturity. Furthermore, Morrison decomposed changes in the spot rate into a change in the ex-ante real component of that rate and a change in the anticipated inflation component. While this decomposition is ad hoc in terms of the Vasicek model, a considerable literature exists which suggests that anticipated inflation is an important determinant of interest rates. The variability of ex-ante real rates is a matter of some controversy (see Fama (1975) and Nelson and Schwert (1976)). Morrison's estimating equation allows for changes in the ex-ante real component of spot rates. If deviations in the real component of spot rates are considered temporary, but deviations in current inflation anticipations are correlated with changes in inflation anticipations for future periods, we would expect these two components to have different effects on forward rates. Consequently, the estimating equation permits the impact of the real and the inflationary effects of the 1-period spot rate on yields to maturity to be different.

The form estimated was:

$$
\frac{d r_{k}}{R_{F k}}=\frac{d r r_{1}}{R R_{F I}} e^{-\gamma_{0}-\gamma_{1} k}+\frac{d i_{1}}{I_{1}} e^{-\beta_{0}-B_{1} k},
$$

where:

$$
\begin{aligned}
r_{k} & =\text { the k-period risk-free rate } \\
R_{F k} & =1+r_{k}
\end{aligned}
$$




$$
\begin{aligned}
\mathrm{rr}_{1} & =\text { real one-period rate } \\
\mathrm{RR}_{\mathrm{F} 1} & =1+\mathrm{rr}_{1} \\
I_{1} & =\text { one-period inflationary expectation } \\
\mathrm{I}_{1} & =1+i_{1} \\
\mathrm{rr}_{1}+i_{1} & =\mathrm{r}_{1} .
\end{aligned}
$$

The unit time period chosen to estimate equation (7) was one month. Term structures for default-free securities were estimated for thirty months from January 1973 through July 1975 using the tax-adjusted, cubic-spline method developed by McCulloch (1975). The data used were Salomon Brothers quotations for the last trading day of each month. This provided fifteen independent sets of adjacent term structures to be used in computing proportional rate changes for different maturities. Thirty maturities, ranging from two months to ten years, were used for each term structure, for a total of 450 pooled observations. ${ }^{2}$

The nominal spot rate obtained for each of the term structures was decomposed into an ex-ante real component, and an inflationary anticipations component. Inflationary expectations were estimated by using the methodology in the Nelson and Schwert (1976) article.

Equation (6) was estimated by a two step process. First, the coefficients of the real component $\left(\gamma_{0}\right.$ and $\left.\gamma_{1}\right)$ were estimated by 1gnoring the inflation term, performing a log transform, and using linear regression. The estimated coefficients were then used to form a set of residuals $\left(\mathrm{dr}_{k} / \mathrm{R}_{\mathrm{Fk}}\right.$ unexplained by $\left.\mathrm{drr}_{1} / \mathrm{RR}_{\mathrm{Fl}}\right)$. These residuals were then used to estimate the inflationary coefficients $\left(B_{0}, B_{1}\right)$, again using linear regression on a $\log$ transform, this time ignoring the real term. The

2 Because of the estimation technique employed a few periods which displayed no spot rate changes could not be used. 
results are shown in Table 2. As the table shows, coefficients on each term have the correct sign and are statistically significant. As a check, the procedure was repeated with the coefficients estimated in the reverse order. While the results were not identical, the sign and general magnitude of each coefficient remained unchanged. More important, the general pattern of transmission discussed below remains the same with the alternative specification. This, combined with some preliminary results by other researchers indicating that the IRE estimates are fairly insensitive to the transmission process, indicated that the results as shown in Table 2 should be sufficient for use in the analysis which follows.

Table 2. Regression of Nominal Rate Changes on Real Rate Changes and Changes in Inflationary Expectations

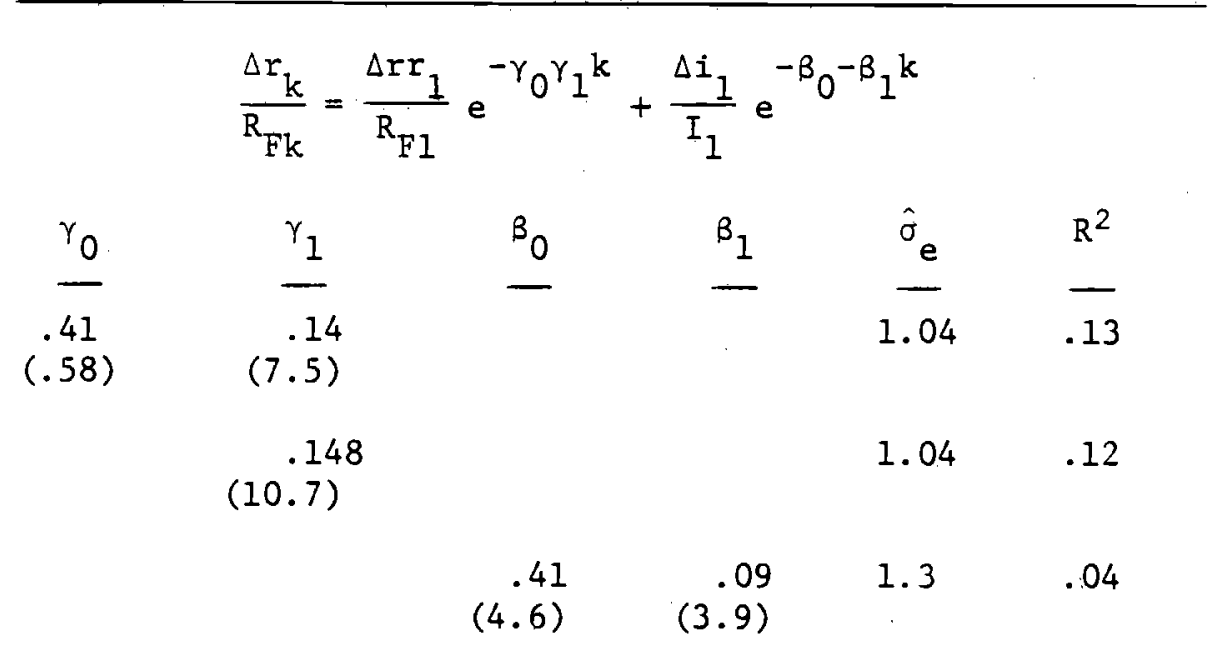

The resulting empirical model of interest rate changes is

$$
\frac{d r_{k}}{R F_{k}}=\frac{d r r_{1}}{R R_{F 1}} e^{-.148 k}+\frac{d i_{1}}{I_{1}} e^{-(.41+.09 k)}
$$


Interest rate elasticity based on an empirical model of interest rates

With the interest rate process described by equation (7), the expression for the proportional change in the present value of a bond may be written as

$$
\frac{d P V_{s}}{P V_{s}}=-\frac{\sum_{i=1}^{t}\left(S_{i} \delta_{i}\right)\left(\left(\frac{d r r_{1}}{R R_{F 1}}\right) e^{-.148 i}+\left(\frac{d i}{I_{1}}\right) e^{-.41-.09 i}\right) \cdot i}{\sum_{i=1}^{t} S_{i} \delta_{i}}
$$

A given proportional change in one plus the spot rate will be distributed between the proportional change in the real component and the proportional change in the inflationary component. By examining equation (8), we can see that the estimated IRE of a bond for a given spot rate change will be a weighted average of one, the IRE due to the real component, and two, the IRE due to the inflationary component, with the weights being the respective contributions of those components to the proportional change in the spot rate. These two IRE relationships are

$$
\operatorname{IRE}(\text { real })=\frac{-\sum_{i=1}^{t}\left(S_{i} \delta_{i}\right) \cdot i \cdot e^{-.148 i}}{\sum_{i=1}^{t}\left(S_{i} \delta_{i}\right)}
$$

$$
\operatorname{IRE}(\text { inflation })=\frac{-\sum_{i=1}^{t}\left(S_{i} \delta_{i}\right) \cdot i \cdot e^{-.41-.09 i}}{\sum_{i=1}^{t}\left(S_{i} \delta_{i}\right)}
$$


In Table 3, we have reported some interest rate elasticities (proportional change in value per $1 \%$ change in the spot rate) based on equations (9) and $\left(9^{\prime}\right)$. Two of the loans considered in Table 3 are directly comparable to the loans reported in Table 1. The more rapid fall-off in the effects of changes in the real component of spot rates is apparent from the lower IRE values for this case. The IRE was also calculated for a conventional $10 \%$ coupon, 10 year bond using a flat (10\%) term structure and also using the estimated term structure for May 1975. In the least extreme case for this longer term bond (change in inflationary expectations only), the IRE based on the empirical model of interest rate changes is 3.53 which is just over $50 \%$ of the IRE of 6.76 , obtained using Macaulay's duration.

Table 3. Interest Rate Elasticities (IRE) from Equations (9) and ( $9^{\prime}$ )

\begin{tabular}{ccccc}
\multicolumn{2}{c}{ Flat } & \multicolumn{1}{c}{$\begin{array}{c}\text { May } 1975 \\
\text { IRE }\end{array}$} & & Term Structure \\
\cline { 1 - 2 } IRE & IRE & & IRE \\
Equal Pay- & $10 \%$ Coupon, $10 \%$ Coupon, & & $10 \%$ Coupon, \\
ment Loan & 3 yr Bond & $10 \mathrm{yr}$ Bond & & $10 \mathrm{yr}$ Bond \\
\hline
\end{tabular}

Change in real

rate only

$-2.08$

$-2.43$

$-2.40$

Change in inflationary anticipations only $-1.73$ $-2.31$ $-3.55$ $-3.53$

The method used to obtain the interest rate elasticities in Table 3 is directly applicable to the estimation of interest rate elasticities for the securities in a financial institution's investment portfolio. As noted earlier, this measure of the proportional change in net worth incorporates only the effects of changes in the level and structure of defaultfree interest rates. For a security which is not issued by the federal government, for example state and local government securities, there will 
be other sources of change in the security's value. To the extent that these other sources of change can be incorporated into a model of interest rate changes that can be estimated, the approach discussed here may be broadened to provide a measure of the proportional change in security value as a function of a vector of determinants of that change.

Whether the somewhat restrictive default-free interest rate elasticity, or a more comprehensive measure of the potential change in investment portfolio value is used, the estimate of the price sensitivity of the investment portfolio should be useful information for the regulators of financial institutions. In the case of the IRE estimates given by equations (9) and ( $\left.9^{\prime}\right)$, this information is relatively easy to obtain. A program exists for estimating the default-free term structure from U.S. government bond data (see McCulloch (1975)). A periodic, perhaps weekly, estimation of the term structure could be used to provide examiners with timely estimates of the discount function (i.e., the $\delta_{i}$ values). Equations (9) and (9') may be programmed on a hand-held, programable calculator. By taking an appropriately designed sample of the securities in an investment portfolio, estimating their interest rate elasticities, and then taking a weighted average of the sample elasticities using known portfolio weights, the examiner could obtain an estimate of the sensitivity of that investment portfolio to changes in the short-term, default-free interest rate.

There remain a number of open questions regarding the application of interest rate elasticities (i.e., generalized duration concepts) in the prediction of expected security price changes. In terms of the model used by Morrison, one such question concerns the assumption that interest rate changes are independent of the level of interest rates. Intuition and 
observation suggest that tax effects are likely to be related to the extent to which securities are selling above or below par, and hence that the current level of rates (relative to past levels) should be important. Furthermore, there is evidence (see Nadauld (1978)) that the model used by Morrison tends to underpredict changes in longer term rates. Perhaps more importantly, recent research by Lanstein and Sharpe (1978) has shown that very strong assumptions about the correlation of nonsystematic changes in interest rates are necessary to theoretically justify the use of (generalized) duration as a determinant of the ex-ante interest rate risk of a security. However, they also give evidence that even a crude measure of duration (i.e., Macaulay's definition) is significantly related to components of security risk.

\section{Interest Rate Elasticity of Financial Institutions}

Samuelson (1945) used duration to study the effects of interest rate changes on financial institutions. To derive his result, let:

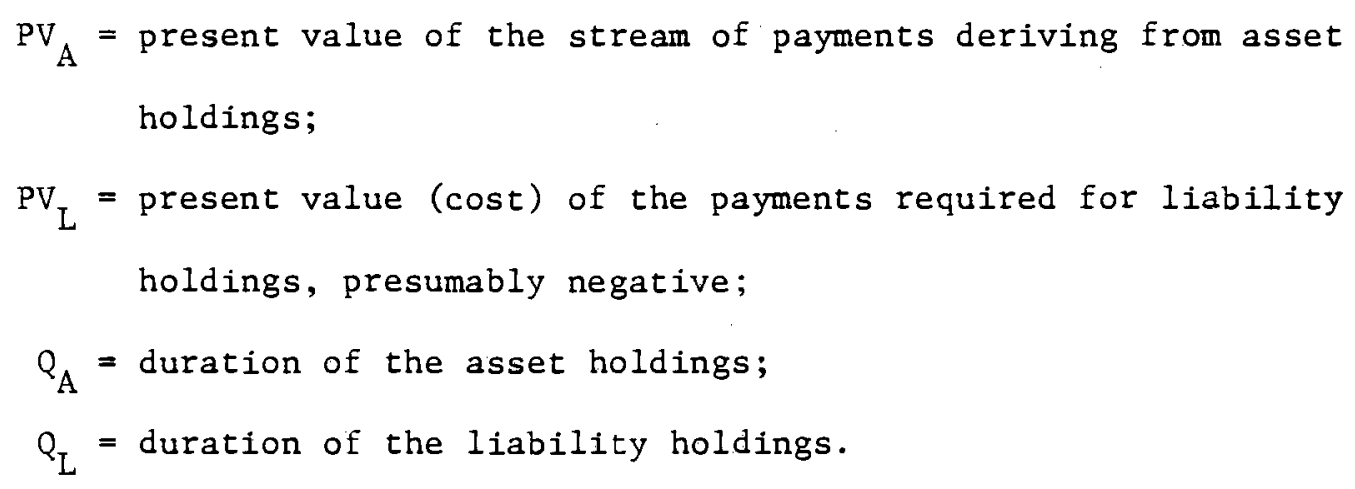
holdings;

$P V_{L}=$ present value (cost) of the payments required for liability holdings, presumably negative;

$\mathrm{Q}_{\mathrm{A}}=$ duration of the asset holdings;

$Q_{L}=$ duration of the liability holdings.

\section{Assuming that:}

1) spot and forward rates on all liabilities and all assets change by the same amount; and

2) the amount of each asset and liability held by the bank remains unchanged when rates change, 
the above result can be applied directly to the asset and liability portfolios of a bank giving:

$$
\frac{d P V_{A}}{P V_{A}}=-Q_{A} \frac{d h}{h}
$$

for the asset portfolio, and

$$
\frac{d P V_{L}}{P V_{L}}=-Q_{L} \frac{d h}{h}
$$

for the liabilities. Note that the above assumptions imply that the asset portfolio is essentially a fixed-payment, fixed maturity bond, which the bank has purchased, with the liability portfolio equivalent to a bond with fixed payments and fixed maturity, which the bank has isqued.

Defining the capital or net worth of the bank by $P V_{T}=P V_{A}+P V_{L}$, the Samuelson result is:

$$
\frac{\mathrm{dPV}_{\mathrm{T}}}{\mathrm{PV} \mathrm{V}_{\mathrm{T}}}=-\frac{\left(\mathrm{Q}_{\mathrm{A}} \mathrm{PV} \mathrm{A}_{\mathrm{A}}+\mathrm{Q}_{\mathrm{L}} \mathrm{PV} \mathrm{L}_{\mathrm{L}}\right)}{\mathrm{PV}_{\mathrm{A}}+\mathrm{PV} \mathrm{V}_{\mathrm{L}}} \cdot \frac{\mathrm{dh}}{\mathrm{h}}=-\mathrm{Q}_{\mathrm{T}} \frac{\mathrm{dh}}{\mathrm{h}} ; \mathrm{PV}_{\mathrm{T}}>0 .
$$

Equation (10) says that the percentage change in capital is proportional to the percentage change in interest rates, with the constant of proportionality, $-Q_{T}$, being the negative of the duration of the bank as a whole. The bank's duration is, in turn, a weighted average of the durations of the asset and liability holdings, with the weights being the fractional contributions to total present value.

A major implication of $(10)$ is that a necessary (but not sufficient) condition for a bank to be made better off by a rate increase is that its liabilities be of longer duration than its assets, i.e., that $Q_{L}>Q_{A}$. Since the prevailing opinion appears to be that banks' borrowings are of 
shorter term than their lendings, it seems more likely that $Q_{A}>Q_{L}$, from which it follows that a bank would be made worse off by a rate increase. The result, of course, is both intuitive and a result of the simplifying assumptions on which the analysis is based. The "bank" is in fact equivalent to an investor who simultaneously purchases a bond with duration of, say, ten years and issues a bond of equal value with a duration of two years. If rates subsequently rise, he must either finance the remaining eight years of his investment at a higher cost or sell his investment at a discount from his purchase price, both of which entail losses relative to the earlier situation.

As we have seen from our discussion of the interest rate elasticity of bonds, an assumption implicit in the conventional duration formulation is that forward rates change in the same proportion as spot rates. Empirically this does not appear to be a warranted assumption. Clearly we can proceed as we did in the case of bonds, using an empirically estimated model of interest rate changes to formulate a generalized duration for a financial institution. For financial institutions with assets that are longer-lived than liabilities, the interest rate elasticities of net worth will tend to be smaller when based on the interest rate process summarized in equations (9) and ( $\left.9^{\prime}\right)$ than if these net worth elasticities were based on the conventional duration calculation.

Adopting a generalized duration formulation does not solve all of the problems encountered in calculating an interest rate elasticity for the net worth of financial institutions. The major difficulties which remain are:

1. Not all of a bank's assets and liabilities have fixed payment streams and a well-defined maturity. Therefore, a method of 
estimating the cash flows associated with these assets and liabilities must be developed.

2. Many of a bank's assets and liabilities are not market instruments and do not have an observable market value. To study the sensitivity of the bank's net present value, these market values must be imputed from the anticipated cash flows.

3. The cash flows are neither single-period nor risk-free, which complicates the discounting technique.

In the analysis that follows, we have attempted to deal with most of these problems. The approach taken is a simulation based on an analysis of the impact of macroeconomic variables on bank cash flows using data normally available to bank regulatory agencies. The selected sub-sector of the bank is intended to reflect the most important characteristics of a wholesale bank (i.e., a bank dealing mainly in corporate and commercial lending supported by corporate and commercial demand and time deposits). The asset categories modeled are commercial loans and cash. The liabilities are demand deposits, purchased funds (negotiable certificates of deposit, NCDs) and equity capital. 3

Modeling Bank Cash Flows

The bank to be considered has only one type of earning asset (commercial loans) and one interest-bearing liability (NCDs). In addition, the bank obtains some of its funding from demand deposit balances held by business firms. Demand deposit balances and NCDs outstanding imply cash

${ }^{3}$ These asset/liability categories are few even for a money center, wholesale bank with the main omissions being real estate loans and the investment portfolio. The contribution of the latter to net worth elasticity is a straightforward application of the method discussed in the previous section of this paper. An application of generalized duration estimation for a real estate portfolio is contained in Nadauld (1978). 
balances in the form of required and excess reserves. In the simulations described here, it is assumed that the ratio of total book assets to book equity (capital ratio) is held constant through time and this assumption completes the specification of the bank's balance sheet.

To estimate the interest-rate elasticity of the bank's net worth, we must estimate the payout stream to the bank's owners and the response of that stream to changes in the level and structure of interest rates. The payout stream consists of net income for each future time period, less the change in equity capital implied by the constant capital ratio assumption. Models of these cash flows are described in detail in Morrison (1977). In summary, the structure of system estimated by Morrison is:

(1) a model of future commercial loan commitments was developed,

(2) a model of future commercial loan volume (in part dependent on commitments) was developed,

(3) future demand deposit balances (in part dependent on loan volume and loan commitments) were modeled and used to project the cash assets for the bank,

(4) the period by period estimates of future total assets (loan volume plus cash assets) times the assumed capital ratio provided an estimate of equity capital and total assets less demand deposits and equity capital provided an estimate of the future volume of purchased funds,

(5) models of the future yields on loans and the future NCD rates were estimated,

(6) the periodic future net income was obtained by multiplying the estimated loan volumes by estimated loan yields and subtracting the estimated volume of purchased funds times the estimated NCD rates, and 
(7) the periodic payout to bank owners was obtained by subtracting the estimated change in equity capital for each period from the estimated net income for that period.

\section{Commercial loan commitments}

Morrison's model of commercial loan commitments is based on a disequilibrium credit market. Firms are assumed to face uncertainty regarding the timing of future transactions. Each firm chooses between fixed maturity borrowing and loan commitments by comparing the minimum expected cost of a loan with the expected cost of a commitment. Given this description of the loan choice problem it can be shown that the relative demand for commitments ( 1 ) decreases as the rate charged for funds borrowed on commitments increases, (2) increases as the uncertainty associated with future transaction dates increases, (3) decreases as the loan size increases (absolute commitment demand may increase), and (4) increases as the rate on fixed maturity borrowing increases.

The bank is assumed to set the commitment fee, the loan rate, and the maximum commitment it is willing to make to any customer. The actual commitment size is then the minimum of the firm's demand and the maximum supply. For the bank to set rationally both the rate and a quantity. maximum, thereby introducing the possibility of non-price rationing, it must be that the bank can increase the expected value of the loan by decreasing the loan size below the amount demanded at the rate that is optimal for the bank. Briefly, this could be true for a pair of reasons:

1) Banks potentially have some degree of monopoly power over at least some customers, but the degree of collusion necessary to maximize joint profits would be socially and legally unacceptable. An alternative is to classify customers into groups based on 
riskiness, tie the rate for each class to the least risky rate, and engage in price-leadership behavior by making that rate (and changes in that rate) widely publicized. To the extent that riskier customers also have lower price elasticities of demand, this process can be successful in achieving some degree of price discrimination.

2) Since it is probably not operationally feasible to have a great number of risk classes (traditionally, spreads over prime are quoted in half percent intervals), and the number of customers will exceed the number of classes, it will be necessary to charge similar but not identical customers the same rate. In such a situation, it may be optimal to ration the amount of credit extended to the riskiest customers in each class. The existence of usury ceilings strengthens this effect.

In sumary, the existence and rationality of non-price credit rationing derives from both competitive and institutional factors.

We assume that the loan officer of the bank is trying to maximize expected profit on the commitment relative to an uncertain opportunity cost over a single-period horizon. This optimization process leads to a supply of commitments which is a function of a pair of loan rate parameters (among other things). If the bank were able to set these parameters differently for each borrower having a different riskiness, there would be no rationing. However, if--as is assumed here--the bank charges the same rate for a group of borrowers who are heterogeneous in terms of risk, the commitment demand for the riskiest borrowers in the group may be greater than the optimum commitment supply. Therefore, actual commitments will be the smaller of two numbers: the borrower's optimum comitment demand, or the bank's maximum supply. 
Given this description of the bank's optimization problem, it can be shown that the supply schedule displays certain properties: (1) the maximum commitment supplied approaches zero as the loan rate or the commitment fee gets arbitrarily large, (2) the maximum commitment supplied decreases as the bank's opportunity cost increases, (3) under reasonable conditions, the maximum supply decreases with increases in the uncertainty of the opportunity rate, and (4) an increase in the loan rate increases the maximum commitment supply.

\section{Estimation of commercial loan commitments}

The major problem in estimating disequilibrium models is that the observed quantity may not satisfy both the supply and demand schedules. The practical importance of the problem is demonstrated in recent studies of the market for housing starts by Fair and Jaffee (1972) and of the watermelon market by Goldfeld and Quandt (1975). In estimating the loan commitment model, Morrison followed the so-called quantitative method described by Fair and Jaffee. Using this approach, the model derived earlier for commitment supply and demand may be written as:

$$
\begin{aligned}
& D_{t}=\alpha_{0}+\alpha_{1} I_{t}+\alpha_{2} \operatorname{Std}\left(T_{t}\right)+\alpha_{3} P_{t}+\alpha_{4} C P_{t}+\varepsilon_{t}^{d} \\
& S_{t}=\beta_{0}+\beta_{1} I_{t}+\beta_{2} \operatorname{Std}\left(I_{t}\right)+\beta_{3} P_{t}+\beta_{4} L E_{t}+\varepsilon_{t}^{S} \\
& Q_{t}^{*}=\operatorname{Min}\left(S_{t}, D_{t}\right),
\end{aligned}
$$

where:

$$
\begin{aligned}
I_{t}= & \text { opportunity rate during month } t \text { (secondary 3-month } C D \\
& \text { rate) } \\
\operatorname{Std}\left(T_{t}\right)= & \text { measure of economic uncertainty (12-month moving stand- } \\
& \text { ard deviation of gross business sales) }
\end{aligned}
$$




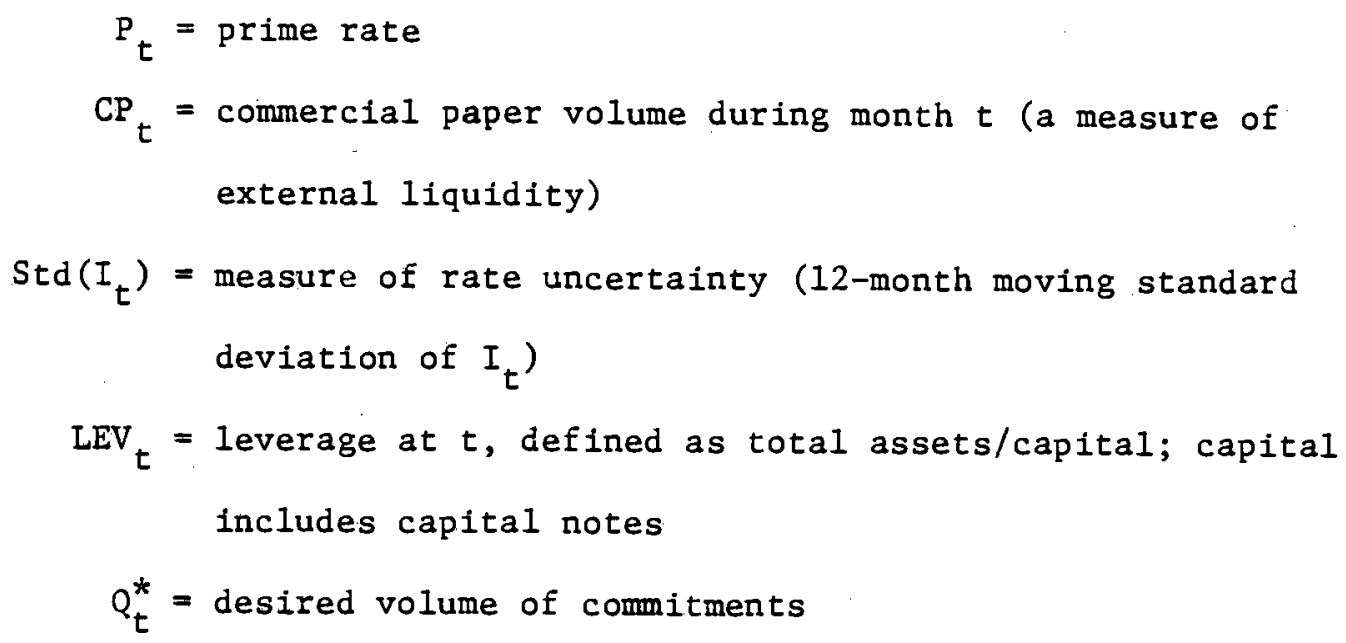

In estimating the disequilibrium equations, the following equation for excess demand was used:

$$
D_{t}-S_{t}=\frac{1}{\gamma} x_{t}
$$

where $x_{t}$ is a measure of the bank's willingness to make loans. 4

The final specification is a lag adjustment in the actual volume of commitments. This specification is justified on the basis of prenegotiated contracts and other institutional factors which prevent immediate adjustment to desired levels of commitments. Assuming that a stock-adjustment process is appropriate, we have:

$$
\Delta Q_{t}=\lambda\left(Q_{t}^{*}-Q_{t-1}\right)
$$

where:

$Q_{t}=$ actual commitments outstanding during month $t$

$\lambda=$ coefficient measuring the speed of adjustment

4 The bank involved participates in the Federal Reserve's Quarterly Survey of Bank Lending Practices, a survey intended to measure the nonprice lending practices of commercial banks. $X_{t}$ is set equal to the first principal component of the survey responses in month $t$. 
Using monthly microeconomic data from a major bank and monthly macroeconomic data from an aggregate macroeconomic model, the loan commitment model was estimated over the period January 1974 -May $1976 .^{5}$ The resulting equations for forecasting loan commitments are given in Table 4.6

Table 4. Forecasting Equations in Loan Commitments

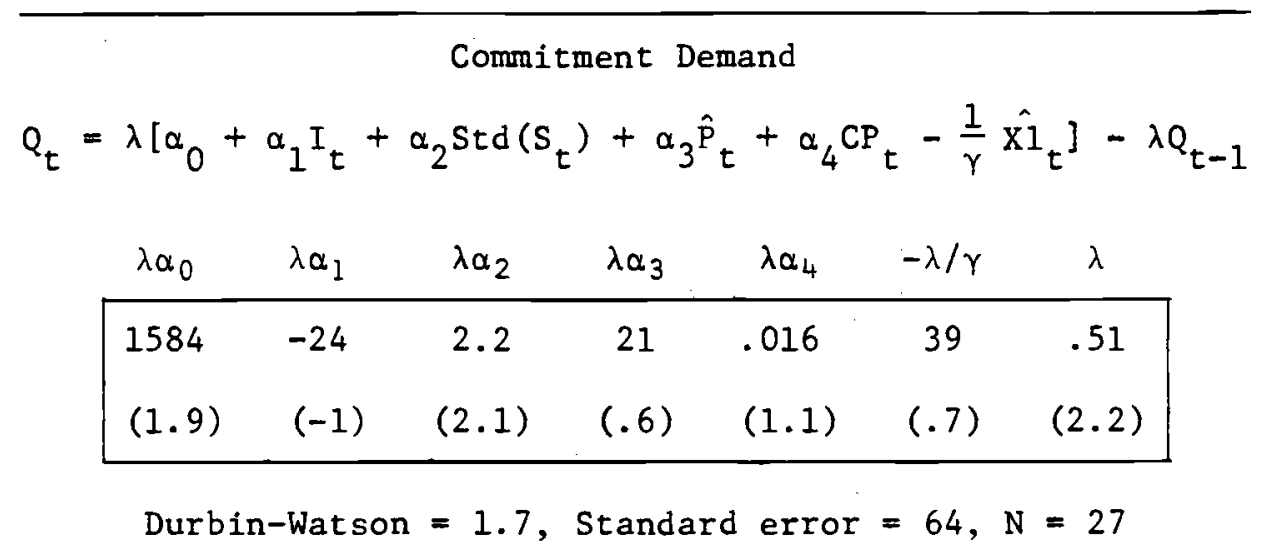

Commitment Supply

$$
\begin{aligned}
& \Delta Q_{t}=\lambda\left[B_{0}+B_{1} I_{t}+B_{2} S t d\left(I_{t}\right)+B_{3} \hat{P}_{t}+B_{4} L E V_{t-1}-\frac{1}{\gamma} \hat{X 2}_{t}\right]-\lambda Q_{t-1} \\
& \begin{array}{lllllll}
\lambda B_{0} & \lambda \beta_{1} & \lambda B_{2} & \lambda B_{3} & \lambda B_{4} & -\lambda / \gamma & \lambda
\end{array} \\
& \begin{array}{lllllll}
3216 & -69 & -70 & 74 & -41 & -73 & .59
\end{array} \\
& \begin{array}{llllll}
(3.2) & (-2.5) & (-.25) & (2.6) & (-2.1) & (-1.5)
\end{array} \\
& \text { Durbin-Watson }=2.4 \text {, Standard error }=59, \mathrm{~N}=26
\end{aligned}
$$

where: $I_{t}, C P_{t}$, Std $\left(S_{t}\right), \operatorname{Std}\left(I_{t}\right)$, and $L_{E V}$ are as defined earlier. $\hat{x}_{t}$ is the first stage regression estimate of the credit rationing proxy for

${ }^{5}$ A major problem in doing empirical research at the bank level is the lack of consistent data for the microeconomic variables. The data used by Morrison were created by a management information system which began operating in January 1974.

6 The terms in parentheses below the coefficient estimates are t-statistics for the coefficient. The mean value of the dependent variable was 129. A two-stage regression with the prime rate and rationing proxy as endogenous variables was used. 
periods of excess demand, $\hat{\mathrm{X}}_{t}$ is the estimated credit rationing proxy for periods of excess supply, and $\hat{P}_{t}$ is the first stage regression estimate of the prime rate. 7

\section{Loan volume}

The loan volume for the bank is determined by the credit needs of its customers, the rate differentials between loans and other sources of credit, and the severity of commitment rationing. Essentially, once a commitment is made, the bank's only influence over whether or not the line is used is through variations in the prime rate. A model of loan demand becomes a model of loans outstanding, except for periods of rationing.

Building on previous studies (Goldfeld (1966) and Jaffee (1971)), Morrison modeled loan demand as a function of borrowers'asset stocks with the choice of loan financing instead of direct financing being influenced by the spread between the rate paid on loans and the rates paid on direct forms of financing. In the absence of non-price rationing, the specific form of the loan volume equation would be:

$$
\begin{aligned}
L_{t}= & b_{0}+b_{1} K_{t}+b_{2} T_{t}+b_{3} z_{t}+b_{4}\left[\left(r_{C P}-P\right)_{t} T_{t}\right] \\
& +b_{5}\left[\left(r_{A A A}-P\right)_{t} T_{t}\right]-b_{6} K_{t-1}-b_{7} T_{t-1}-b_{8} z_{t-1}+(1-\lambda) L_{t-1}
\end{aligned}
$$

where

$$
\begin{aligned}
\mathrm{K}_{t} & =\text { the fixed investment of borrowers } \\
\mathrm{T}_{t} & =\text { gross business sales (a proxy for transactions assets) } \\
\mathrm{Z}_{\mathrm{t}} & =\text { inventory stocks held by borrowers } \\
\mathrm{r}_{\mathrm{CP}} & =\text { the commercial paper rate } \\
P & =\text { the prime rate }
\end{aligned}
$$

${ }^{7}$ A discussion of the estimation of the credit rationing proxies and of the prime rate follows. 


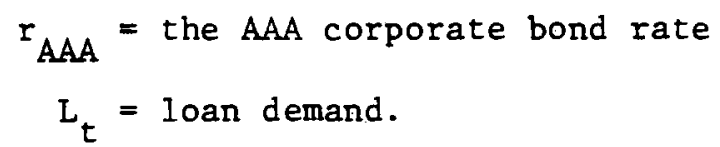

In the presence of rationing, the observed quantity of loans may differ from the quantity demanded. A bank cannot ration loans directly except in the case of a line of credit which is completely used. However, the - rationing of new commitments may cause customers with unused commitments to seek financing elsewhere, or to defer expenditures rather than use up existing commitments. For either case, the loan demand function will overstate actual demand when commitments are being rationed. Letting $R_{t}$ be the reduction in loan demand due to commitment rationing, the observed quantity of loans outstanding becomes:

$$
L_{t}^{r}= \begin{cases}L_{t} & \text { if there is no rationing } \\ L_{t}-R_{t} & \text { if there is rationing }\end{cases}
$$

It is assumed that $R_{t}$ is proportional to $X I_{t}$ (the positive values of the first principal component of the FRB loan survey responses) and $\triangle C P t_{t}$ (the change in the volume of commercial paper outstanding). The constant of proportionality is assumed to depend on $U_{t-1}$ (the lagged ratio of commitment usage). Making these substitutions, the equation to be estimated for loan volume prediction becomes:

$$
L_{t}^{r}= \begin{cases}L_{t} & \text { if } x_{t} \leqq 0 \\ L_{t}-\left(a_{0}+a_{1} U_{t-1}\right)\left(b_{0} X_{t}+b_{1} \Delta C P_{t}\right) & \text { if } x_{t}>0\end{cases}
$$




\section{Estimation of loan volume}

The desired specification of the loan volume equation calls for data on the assets (fixed investment, inventory, and transactions assets) of the bank's actual and potential customers. Since these data are not available, it was assumed that the values for the bank's customers were proportional to the aggregate figures. Furthermore, since consistent aggregate series are not available for all variables in the loan volume equation, the equation was estimated in first difference form. An examination of the results for the full model suggested that the lagged dependent and the lagged customer asset variables were not contributing to the explanation of loan volume in a significant manner. Consequently, for the estimate which was used in subsequent simulations these terms and the insignificant term for current fixed investment were dropped and the equation was estimated using the Hildreth-Lu (1960) transformation. The resulting equation for forecasting loan volume for the bank is given in Table 5 .

Table 5. Forecasting Equation for Loan Volume

\begin{tabular}{|c|c|c|c|c|c|c|c|}
\hline \multicolumn{8}{|c|}{$\begin{aligned} \mathrm{L}_{t}^{\mathrm{r}}= & \mathrm{b}_{0}+\mathrm{b}_{2} \mathrm{~T}_{t}+\mathrm{b}_{3} \mathrm{Z}_{t}+\mathrm{b}_{4}\left[\left(\mathrm{r}_{\mathrm{CP}}-\hat{\mathrm{P}}\right)_{t} \mathrm{~K}_{t}\right. \\
& -c_{0} \hat{\mathrm{X}}{ }_{t}-c_{1} \hat{\mathrm{X}}_{t} \mathrm{U}_{t-1}-c_{2} \Delta C P_{t} \mathrm{U}_{t-1}\end{aligned}$} \\
\hline $\mathrm{b}_{0}$ & $\mathrm{~b}_{2}$ & $\mathrm{~b}_{3}$ & $b_{4}$ & $\mathrm{~b}_{5}$ & $-c_{0}$ & $-c_{1}$ & $-c_{2}$ \\
\hline-17.8 & 1.24 & 2.74 & -.41 & -.30 & 548 & -1807 & -.12 \\
\hline$(-1.2)$ & $(2.6)$ & $(3.1)$ & $(-2.8)$ & $(-1.1)$ & $(5.2)$ & $(-5.2)$ & $(-3.9)$ \\
\hline
\end{tabular}

Durbin-Watson $=2.2$, Standard error $=30, \mathrm{~N}=26, \rho=-.67$ 
The rationing variable

Since the first principal component of the response to the FRB loan activity survey is a determinant of loan commitments and loan volumes at the bank, we must forecast this factor to carry out the simulation of the bank's net worth elasticity. The specification used for estimating a predicting equation is:

$$
\Delta \mathrm{X}_{t}=\lambda\left[\delta_{0}+\delta_{1}\left(\mathrm{~S}_{t}-\mathrm{Q}_{t-1}\right)-\mathrm{X}_{t-1}\right]
$$

where:

$$
\begin{aligned}
& S_{t}=\text { the supply of commitments during month } t \\
& Q_{t}=\text { the quantity of commitments outstanding during month } t \text {. }
\end{aligned}
$$

After substituting for $s_{t}$, the resulting forecasting equation for the

\begin{tabular}{|c|c|c|c|c|c|c|c|c|}
\hline$\lambda \mathrm{d}_{0}$ & $\lambda \mathrm{d}_{1}$ & $\lambda \mathrm{d}_{2}$ & $\lambda \mathrm{d}_{3}$ & $\lambda \mathrm{d}_{4}$ & $-\lambda d_{5}$ & $-\lambda$ & $\mathrm{R}^{2}$ & $\mathrm{D}-\mathrm{W}$ \\
\hline-4.85 & .15 & .63 & -1.81 & .80 & -.004 & -.67 & .44 & 1.72 \\
\hline$(-.76)$ & $(.40)$ & $(.41)$ & $(-1.9)$ & $(.85)$ & $(-.9)$ & $(-1.5)$ & & \\
\hline
\end{tabular}
change in the rationing proxy is as shown in Table 6.

Table 6. Forecasting Equation for the Change in the Rationing Proxy

\section{$\underline{\text { Loan interest rates }}$}

The forecasting equations for loan commitments, loan volume, and the rationing variable, require a forecast of the prime rate. Furthermore, in order to calculate the income from the loan portfolio, we need a period by period forecast of the yield on the loan portfolio. 
In the model we used, the change in the prime rate is determined by a rate of adjustment factor times the difference between the desired prime rate in the current period and the prime rate for the period just prior. The desired prime rate is taken to be a function of the federal funds rate $\left(r_{f t}\right)$, the bank's loan to deposit ratio (LNDP $\left.f_{t}\right)$, and the bank's leverage ratio $\left(\mathrm{LEV}_{t}\right)$. The speed of adjustment is assumed to be determined by lagged values of changes in the opportunity rate of interest for the bank $\left(\Delta I_{t}\right)$. The resulting forecasting equation for the prime rate is given in Table 7.8

Table 7. Forecasting Equation for the Prime Rate

$$
\begin{aligned}
\overline{\Delta P_{t}=} & \lambda\left[e_{0}+e_{1} r_{f t}+e_{2} L N D P_{t}+e_{3} L E V_{t}+e_{4}\left(r_{f t} \Delta I_{t}\right)+e_{5}\left(r_{f t} \Delta I_{t-1}\right)\right. \\
& \left.+e_{6}\left(r_{f t} \Delta I_{t-2}\right)-P_{t-1}\right]
\end{aligned}
$$

\begin{tabular}{|cccccccccc|}
$\lambda e_{0}$ & $\lambda e_{1}$ & $\lambda e_{2}$ & $\lambda e_{3}$ & $\lambda e_{4}$ & $\lambda e_{5}$ & $\lambda e_{6}$ & $-\lambda$ & $R^{2}$ & $D-W$ \\
\hline .037 & .26 & -.60 & .025 & .006 & .021 & .0005 & -.27 & .84 & 1.77 \\
$(.19)$ & $(5.64)$ & $(-.57)$ & $(1.13)$ & $(.88)$ & $(3.62)$ & $(.1)$ & $(-5.7)$ & & \\
\hline
\end{tabular}

The loan yield will differ from the prime rate because (1) much of the loan portfolio consists of non-prime borrowers, (2) only about half of the loan portfolio floats with the prime rate, and (3) the composition of the portfollo (maturity, percentage of floating loans, etc.) may vary systematically with the level of interest rates. In Morrison (1977), it is shown that under a particular set of assumptions the steady-state

\footnotetext{
$8_{\text {The estimation was by two-stage least squares because of the presumed }}$ simultaneity between the prime rate and other micro variables for the bank. For the subsequent simulations it was necessary to forecast the federal funds rate. A linear regression of the federal funds rate on the 3 month risk-free rate was used for these forecasts.
} 
relationship for the loan yield may be written as a linear function of lagged values of the prime rate. The estimation was based on this model with control variables added to allow for a different relationship during periods of rising rates. Additionally, the coefficients of the estimated equation were constrained to reflect a priori knowledge regarding the proportion of term loans in the portfolio. The estimation procedure used the Hildreth-Lu transformation for serial correlation.

The equation used for the loan yield forecasts is given in Table 8.9

Table 8. Forecasting Equation for Loan Yield

$$
\begin{aligned}
Y_{t}= & g_{0}+g_{1} P_{t}+g_{2} P_{t-1}+g_{3} P_{t-2}+g_{4} P_{t-3}+g_{5}\left(F_{t} P_{t}\right) \\
& +g_{6}\left(F_{t} P_{t-1}\right)+g_{7}\left(F_{t} P_{t-2}\right)+g_{8}\left(F_{t} P_{t-3}\right)
\end{aligned}
$$

\begin{tabular}{|ccccccccc|}
$\mathrm{g}_{0}$ & $\mathrm{~g}_{1}$ & $\mathrm{~g}_{2}$ & $\mathrm{~g}_{3}$ & $\mathrm{~g}_{4}$ & $\mathrm{~g}_{5}$ & $\mathrm{~g}_{6}$ & $\mathrm{~g}_{7}$ & $\mathrm{~g}_{8}$ \\
\hline 1.48 & .43 & .29 & .08 & .1 & -.011 & .002 & .013 & -.004 \\
$(12.3)$ & $(9.3)$ & $(5.3)$ & $(1.4)$ & $(-1.4)$ & $(.3)$ & $(1.6)$ & \\
& $\mathrm{R}^{2}=.89$ & $\mathrm{D}-\mathrm{W}=2.3 \quad$ & $0=.85$ & & \\
\hline
\end{tabular}

Demand deposit volume

There are three major determinants of demand deposit volume:

1) compensating balances, usually some percentage of comitments plus some percentage of outstandings (loans);

2) active balances, for use in meeting a firm's required disbursements (payroll, taxes, etc.); and

9 Because of the a priori constraints, independent t-statistics are not obtained for $g_{4}$ and $g_{8}$. $F_{t}$ is a control variable which is 1 during periods of increasing rates and 0 otherwise. 
3) service balances, used to cover the activity charges associated with 2).

If the different types of deposits were recorded separately, different models could be developed for each type. Compensating balances could be estimated as a function of loans and commitments, with active and service balances depending on transactions volume and the level of interest rates. Unfortunately, no distinction is made on the balance sheet among the different deposit types, so one model will have to suffice for all three. The model which was estimated assumes that demand deposit volume is a linear function of commitment volume $\left(Q_{t}\right)$ and loan volume $\left(L_{t}\right)$ with the coefficients of these two factors being dependent on the current prime rate.

The demand deposit forecasting equation is given in Table 9.

Table 9. Forecasting Equation for Demand Deposit Volume

\begin{tabular}{|c|c|c|c|c|c|}
\hline & $=h_{1} Q_{t}$ & $\left(Q_{t} P_{t}\right.$ & ${ }_{3} L_{t}+$ & $\left.P_{t}\right)$ & \\
\hline$h_{1}$ & $h_{2}$ & $h_{3}$ & $h_{4}$ & $\mathrm{R}^{2}$ & $D-W$ \\
\hline-.8 & .11 & .4 & -.05 & .53 & 2.2 \\
\hline$(-1.9)$ & $(2.0)$ & $(3.2)$ & $(-2.2)$ & & \\
\hline
\end{tabular}

\section{NCD rate}

The final factor which must be forecast for the net worth simulations is the rate paid on purchased funds which in this study was taken as the 3-month rate on Negotiable Certificates of Deposit. Since the basic rates driving the simulation are the risk-free rates, an attempt was made to find a stable relationship between the 3-month risk-free rate and the 3month NCD rate. Due to serial correlation in the residual of least squares 
estimates, the Hildreth-Lu transformation was used. The resulting equation for forecasting the spread between the 3-month NCD rate and the 3-month risk-free rate $\left(S P R D_{t}\right)$ is given in Table $10 .^{10}$

Table 10. Forecasting Equation for the NCD Rate

\begin{tabular}{cccccc}
\hline \multicolumn{5}{c}{$S{ }^{S P R D} D_{t}=j_{0}+j_{1} r_{t}+j_{2} r_{t}$} \\
$j_{0}$ & $j_{1}$ & $j_{2}$ & $R^{2}$ & $D-W$ & $\rho$ \\
\hline-2.57 & .03 & .55 & .37 & 1.6 & .75 \\
$(-2.6)$ & $(.8)$ & $(4.5)$ & & & \\
\hline
\end{tabular}

\section{A Model of Net Worth and Net Worth Elasticity}

In addition to the problem of predicting future cash flows to the bank's owners, one must also specify a method for calculating the current value of those cash flows and for predicting the effects of changes in interest rates on that value. The approach we have taken is based on the following valuation model developed by Rubinstein (1975): ${ }^{11}$

$$
P V=\sum_{t=1}^{\infty} \frac{E\left(X_{t}\right)-\left[\operatorname{cov}\left(X_{t 1}-R_{m t}^{-b}\right) / E\left(R_{m t}^{-b}\right)\right]}{R_{F t}}
$$

${ }^{10} \mathrm{r}_{t}$ is the 3 -month risk-free rate.

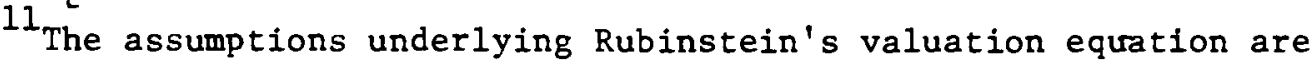
(1) if two securities have the same payoff in all future states, they will have the same current price, (2) investors maximize the expected utility of compensation over their lifetimes and their utility functions are concave, additive in consumption at each date, and never evidence satiation, (3) financial markets are perfect, competitive, and Pareto-efficient, and (4) there is weak aggregation and investors evidence constant proportional risk aversion. While these assumptions are restrictive, they lead to a simple, closed-form equation for valuing arbitrary cash flow streams in a multiperiod setting. 
where

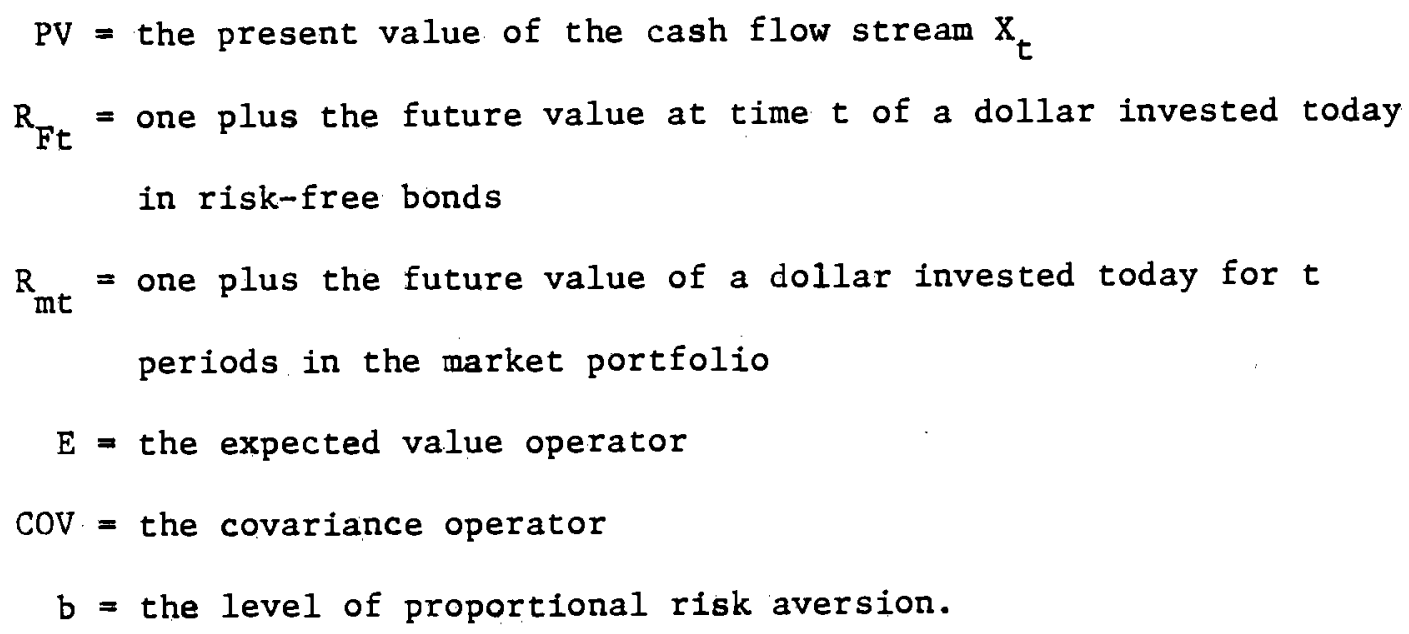

By making some simplifying assumptions, (16) can be used to derive an interest-rate elasticity framework. First, suppose the (t-period spot rate +1 ) on risk-free bonds, $R_{F t}^{1 / t}$, is a function of both time and the short rate, i.e., $R_{F t}^{1 / t}=R_{F}\left(t, r_{0}\right)$. One interpretation of this is that the major determinants of shifts in interest rates is the release of new data containing information that affects relative returns. This assumption is consistent with much of existing term-structure theory, which attempts to explain the shape of the yield curve but takes the level (the value of the short rate, for example) as exogenous (see Kane (1975), for example). Next, we will assume that the probability distribution of the random cash flows is a function of time and the t-period 1 + spot rate, i.e.:

$$
\tilde{x}_{t}=\tilde{x}_{1}\left(t, R_{F}\left(t, r_{0}\right)\right)=\tilde{x}\left(t, r_{0}\right)
$$

Similarly, assume the compound return on the market $(+1)$ is a function of time and the compound return $(+1)$ on risky bonds, or:

$$
E\left(R_{m t}\right)=R_{1}\left(t, R_{F t}\right)=R_{2}\left(t, R_{F}\left(t, r_{0}\right)^{t}\right)=E\left(R_{m}\left(t, r_{0}\right)\right)
$$


Finally, assume that the covariance between the cash flows generated by the project or security in question and the compound return $(+1)$ on the market portfolio raised to the $-b$ power, $\operatorname{cov}\left(x_{t},-R_{m t}^{-b}\right)$, is not a function of interest rates for any $t .{ }^{12}$ With these assumptions, we can then rewrite (16) as:

$$
P V=\sum_{t=1}^{\infty} \frac{E\left(X\left(t, r_{0}\right)\right)-\frac{\operatorname{cov}\left(X_{t},-R_{m t}^{-b}\right)}{E\left(R_{m}\left(t, r_{0}\right)^{-b}\right)}}{R_{F}\left(t, r_{0}\right)^{t}}=\sum_{t=1}^{\infty} \frac{N_{t}}{R_{F}\left(t, r_{0}\right)^{t}} .
$$

Differentiating with respect to $r_{0}$ and dividing by $P V$ to obtain the proportional change gives:

$$
\frac{d P V}{d r_{0}}=\frac{\sum_{t=1}^{\infty} R_{F}\left(t, r_{0}\right)^{-t} \frac{d N_{t}}{d r_{0}}-\sum_{t=1}^{\infty} t \frac{N_{t}}{R_{F}\left(t, r_{0}\right)^{t}} \cdot \frac{\partial R_{F}\left(t, r_{0}\right)}{\partial r_{0}} \cdot \frac{1}{R_{F}\left(t, r_{0}\right)}}{\sum_{t=1}^{\infty} \frac{N_{t}}{R_{F}\left(t, r_{0}\right)^{t}}}
$$

where

$$
\frac{d N_{t}}{d r_{0}}=\frac{d}{d r_{0}}\left[E\left(X\left(t, r_{0}\right)\right)-\frac{\operatorname{Cov}\left(X_{t},-R_{m t}^{-b}\right)}{E\left(R_{m}\left(t, r_{0}\right)^{-b}\right)}\right]
$$

$$
\frac{d N_{t}}{d r_{0}}=\frac{\partial E\left(X\left(t, r_{0}\right)\right.}{\partial r_{0}}+\frac{\operatorname{cov}\left(X_{t},-R_{m t}^{-b}\right) \frac{\partial E\left(R_{m}\left(t, r_{0}\right)^{-b}\right)}{\partial r_{0}}}{E\left(R_{m t}^{-b}\right)^{2}} .
$$

${ }^{12}$ This assumption restricts our analysis to the pure interest-rate elasticity of net worth since it precludes any changes in the riskiness of cash flows which are correlated with changes in the spot rate. 
Equation (18) is an analog to the generalized duration measured obtained for bonds. Note however, that it has not been converted into elasticity terms, but rather gives the proportional change in net worth for a given absolute change in the spot rate. The values calculated using equation (18) may be interpreted as the percentage change in net worth for the bank per 100 basis point change in the spot rate. Another difference from the generalized duration measure for bonds is that the proportional change in net worth for the bank accounts for the effects of changes in interest rates on the future cash flows received by the bank's owners.

Given the forecasts of the periodic payout to the bank's owners which may be obtained using the cash flow forecasting equations given in Tables 4 through 10 and a term structure of risk-free rates, one has the basic data for estimating the current net worth of the bank, using equation (17).

\section{Risk adjustment estimation}

For our estimates the proportional risk aversion factor, b, was taken to be 1 (which implies logarithmic utility). The excess return on the market was estimated as a linear function of the one month risk-free rate. The resulting forecasting equation, based on monthly observations ${ }^{13}$ from 1965-75, is given in Table 11 .

Table 11. Excess Market Return $\left(\mathrm{EX}_{t}\right)$ vs the Risk-Free Rate $\left(r_{t}\right)$

$$
\mathrm{EX}_{t}=\mathrm{a}+\mathrm{br} \mathrm{r}_{\mathrm{t}}
$$

\begin{tabular}{|ccccc|}
$\mathrm{a}$ & $\mathrm{b}$ & $\mathrm{N}$ & $\mathrm{D}-\mathrm{W}$ & $\begin{array}{c}\text { Std } \\
\text { Error }\end{array}$ \\
\hline-.043 & 13 & 119 & 1.81 & .037 \\
$(-2.14)$ & $(2.6)$ & & & \\
\hline
\end{tabular}

13 Both Excess Market Return and the risk-free rate are expressed as one-month returns, i.e., without conversion to an annually-compounded equivalent. 
Finally, to estimate the covariance between the bank's cash flows and the compound market return, it was assumed that (1) market returns are serially uncorrelated, (2) bank cash flows are uncorrelated with lagged market returns, (3) the variability of net interest income is a reasonable proxy for the variability in the net cash flows to the bank's owners, (4) the correlation between the net cash flows and the market return is not a function of time or interest rates, and (5) the variance of the market return is constant. With these simplifying assumptions, the sample correlation between the bank's net interest income and the inverse of the monthly market returns was estimated for the 1969-1975 period. The results were:

$$
\begin{aligned}
\operatorname{Std}\left(1 / \mathrm{r}_{\mathrm{m}}\right) & =.06 \\
\operatorname{Std}(\mathrm{X}) & =1.96 \text { million } \quad \mathrm{N}=69 \text { months } \\
\rho\left(\mathrm{X}, \mathrm{r}_{\mathrm{m}}\right. & -1)=-.22
\end{aligned}
$$

With Std $\left(X_{t}\right)$ and $E\left(r_{m t}\right)$ permitted to depend on the funding strategy employed and on interest rates, the entire risk adjustment term becomes:

$$
\frac{\operatorname{Cov}\left(x_{t},-R_{m t}^{-1}\right)}{E\left(R_{m t}^{-1}\right)}=\frac{E\left(R_{m t-1}^{-1}\right) .22(.06) \operatorname{Std}\left(x_{t}\right)}{E\left(R_{m t}^{-1}\right)}=.0132 \operatorname{std}\left(x_{t}\right) \frac{E\left(R_{m, t-1}^{-1}\right)}{E\left(R_{m, t}^{-1}\right)}
$$

\section{Estimation of future spot rates}

McCulloch (1971) described a procedure for estimating the discount function (i.e., the value today of a certain promise to pay $\$ 1$ at time $t$ for all values of $t$ ) from observed prices. With the additions contained in his later article (McCulloch $(1975 b)$ ), this method was adapted for term structure estimation in this study. Once the discount function is obtained 
by McCulloch's procedure, estimated forward rates for all future periods may be calculated along with the current spot rate.

The estimated forward rates will differ from estimated future spot rates to the extent that the current term structure includes liquidity premia. A number of studies of the liquidity premium have been made, and although many of these studies agree that premia exist, there is considerable disagreement on the details of the liquidity premium structure. Again we have adopted results obtained by McCulloch (1975a) to obtain the mean liquidity premia as a function of the time period for which each premium applies. The resulting estimates of liquidity premia were subtracted from the forward rate estimates to obtain the estimates of future spot rates period by period.

The procedures just described provide two of the three characteristics of risk-free interest rates needed for the simulations of proportional changes in net worth. The estimated discount function is used directly in the calculation of the estimated present value of net worth as shown in equation (17). The estimated future spot rates are a major determinant of the estimates of future cash flows for the bank. The third aspect of riskfree interest rates needed for the simulations is the response of future spot rates and the discount function to changes in the spot rate. This is obtained from the empirical model of interest rate changes discussed earlier and sumarized in equation (7).

\section{Simulation of the Interest-Rate Elasticities of Bank Net Worth}

The calculation of net worth elasticities for the hypothetical wholesale bank examined in this study begins with the selection of a time at which the present value of net worth and its interest-rate sensitivity are to be calculated. A basic interest rate forecast is obtained by the 
methods pioneered by McCulloch and discussed earlier. The term structure is estimated for the base period, forward rates are calculated, and a liquidity premium estimate subtracted from each to give estimates of future one-month rates. The future spot rates are used to forecast prime rates, NCD rates, and expected returns on the market portfolio. Prime rates are used to calculate the loan yield series.

Macroeconomic variable forecasts are taken from publications of the producer of one of the aggregate macroeconomic forecasting services, again as of the base period. ${ }^{14}$ The macro variable forecasts, along with the interest rate forecasts, allow monthly loan volume and commitments to be estimated. With loan volume and commitments forecasts, one can forecast monthly deposit balances. When combined with an assumption about the bank's capital structure, these various forecasts are sufficient to generate cash flow forecasts for the payout stream to the owners of the bank's equity. As noted earlier, the procedure used in this study is to assume that the ratio of total book assets to book equity (capital ratio) is held constant through time. ${ }^{15}$ Recalling that the balance sheet of the simplified model of a wholesale bank includes loans and cash as assets and demand deposits, purchased funds, and equity capital as liabilities, the forecasts of demand deposit volume are used to forecast cash balances. These cash balances plus the estimated loan volume provide a total asset forecast which, when multiplied by the inverse of the assumed capital

14 If no forecasts were published during the base period, the most recent forecasts are assumed to remain in effect. Linear approximations are used if forecasts were other than monthly. When forecasts end before the horizon, the remainder of the values are generated by using an average growth rate based on the forecasts that are provided.

15 This assumption has the advantage of centering attention on a major regulatory measure of capital adequacy but otherwise is arbitrary and used for computation convenience. 
ratio, gives an estimate of book equity. Purchased fund balances are then obtained as the difference between book total assets and the sum of demand deposits plus book equity.

In addition to the expected cash flow forecasts for each future time period, the valuation method we have employed requires estimates of the standard deviation of these cash flows. These estimates were obtained by assuming that the growth rate in the cash flow is from a stationary distribution and is serially uncorrelated. The mean growth rate and the variance of the growth rate needed for these estimates are derived from historical patterns in the bank's net interest income. Since those patterns resulted from a capital ratio of about 22 , an adjustment is made when other capital ratios are assumed. 16

The final problem to be solved before making the calculations is that of choosing a horizon. A horizon of ten years is assumed largely because it appears to be an upper limit for accurate forecasts of forward rates. The end-point problem is solved by assuming that the risk-adjusted book equity at the end of ten years is invested in one-month Treasury bills forever.

There is an added complication in calculating the interest-rate sensitivity of net worth since one is required to calculate the derivative of expected cash flows with respect to the spot rate. This derivative is evaluated by numerical analysis, specifically by the technique of extrapolation to the limit. ${ }^{17}$

16 Using this approach $S t d\left(x_{t}\right)$ increases with $t$ and decreases with the capital ratio. Morrison (1977) also made estimates for which $S t d\left(X_{t}\right)$ was assumed constant for all t. The differences in results were slight and only the results using the growth rate assumption are used here.

17 The method is explained in detail in most elementary numerical analysis texts (see, for example, Conte (1965), pp. 114-120). 


\section{Simulation Results}

Simulations of the market value of net worth for the hypothetical bank and of the interest-rate elasticity of the market net worth are reported for three bases periods, January 1973, January 1974, and May 1975. The estimated yield curves for these three dates are given in Table 12 . The January 1973 curve can be described as mildly upward sloping (173 basis points from $t=0$ to $t=10$ yrs) while the May 1975 curve is sharply upward sloping ( 330 basis points from $t=0$ to $t=10 \mathrm{yrs}$ ). In contrast, the January 1974 curve has a "hump" which peaks at $t=5 \mathrm{mo}$. and is slightly downward sloping over most of the rest of its span. These three curves encompass the main term structure shapes which existed during the period for which the bank data is available.

The estimates of market net worth and the interest-rate elasticities of net worth for various book capital ratios are given in Tables 13 through 15. The market net worth values are the solutions to equation (17) given the previously discussed estimates of the variables in that equation. Clearly, as the ratio of total assets to book equity decreases, the quantity of purchased funds decreases, and the market value accruing to the owners of the equity increases.

Four estimates of the interest-rate elasticities are given. Since the empirical model of interest rate changes in equation (7) shows the response of future spot rates to changes in the current spot rate to be different for spot rate changes due to changes in the real component as compared to changes in the inflation rate, it is possible to estimate the percentage change in the market value of net worth for a 100 basis point change in the real rate and for a 100 basis point change in the inflation rate. $\overline{I R E}_{1}$ and $\overline{I R E}_{2}$ are based on a 100 basis point change in the real 
Table 12. Tax-Adjusted Yield Curve on $1 / 73,1 / 74$, and 5/75

\begin{tabular}{|c|c|c|c|c|c|c|c|}
\hline \multicolumn{2}{|c|}{ Maturity } & \multicolumn{2}{|l|}{$1 / 73$} & \multicolumn{2}{|l|}{$1 / 74$} & \multicolumn{2}{|c|}{$5 / 75$} \\
\hline 0 & & $4.77+$ & .16 & $7.21+-$ & .23 & $4.86+-$ & .58 \\
\hline 1 & mo. & $4.89+$ & .05 & $7.23+$ & .07 & $5.10+$ & .17 \\
\hline 2 & mo. & $5.03+$ & .03 & $7.36+$ & .05 & $5.34+$ & .08 \\
\hline 3 & mo. & $5.19+$ & .02 & $7.53+$ & .03 & $5.57+$ & .06 \\
\hline 4 & mo. & $5.32+$ & .02 & $7.62+$ & .03 & $5.80+$ & .09 \\
\hline 5 & mo. & $5.43+-$ & .02 & $7.63+$ & .03 & $6.02+-$ & .07 \\
\hline 6 & mo. & $5.49+-$ & .02 & $7.60+$ & .03 & $6.22+$ & .07 \\
\hline 7 & mo. & $5.53+$ & .02 & $7.54+-$ & .03 & $6.39+-$ & .07 \\
\hline 8 & mo. & $5.55+$ & .02 & $7.47+$ & .04 & $6.54+$ & .07 \\
\hline 9 & mo. & $5.56+$ & .03 & $7.40+$ & .04 & $6.68+$ & .06 \\
\hline 10 & mo. & $5.58+$ & .03 & $7.34+$ & .05 & $6.80+$ & .05 \\
\hline 11 & mo. & $5.61+$ & .03 & $7.27+$ & .05 & $6.91+$ & .05 \\
\hline 12 & mo. & $5.63+$ & .03 & $7.21+$ & .05 & $7.01+$ & .05 \\
\hline 13 & mo. & $5.66+$ & .03 & $7.16+-$ & .05 & $7.10+$ & .05 \\
\hline 14 & mo. & $5.70+$ & .03 & $7.11+$ & .04 & $7.19+-$ & .05 \\
\hline 15 & mo. & $5.73+$ & .03 & $7.07+$ & .04 & $7.27+$ & .05 \\
\hline 16 & mo. & $5.76+$ & .03 & $7.03+-$ & .04 & $7.35+$ & .05 \\
\hline 17 & mo. & $5.79+$ & .03 & $6.99+$ & .04 & $7.42+$ & .04 \\
\hline 18 & mo. & $5.82+$ & .03 & $6.96+$ & .04 & $7.48+$ & .04 \\
\hline 21 & mo. & $5.91+$ & .03 & $6.89+$ & .04 & $7.65+$ & .03 \\
\hline 2 & yrs. & $5.97+$ & .03 & $6.86+-$ & .04 & $7.78+$ & .04 \\
\hline 30 & mo. & $6.07+$ & .02 & $6.85+-$ & .02 & $7.96+$ & .04 \\
\hline 3 & yrs. & $6.13+$ & .02 & $6.85+-$ & .03 & $8.07+$ & .05 \\
\hline 4 & yrs. & $6.18+$ & .02 & $6.82+-$ & .03 & $8.17+$ & .05 \\
\hline 5 & yrs. & $6.21+$ & .02 & $6.77+$ & .02 & $8.17+$ & .04 \\
\hline 6 & yrs. & $6.27+$ & .02 & $6.74+$ & .02 & $8.15 t-$ & .04 \\
\hline 7 & yrs. & $6.34+$ & .02 & $6.74 t$ & .02 & $8.14+$ & .06 \\
\hline 8 & yrs. & $6.42+$ & .02 & $6.77+$ & .02 & $8.14+$ & .07 \\
\hline 9 & yrs. & $6.47+$ & .02 & $6.82+-$ & .03 & $8.15+$ & .07 \\
\hline 10 & yrs. & $6.50+-$ & .02 & $6.88+-$ & .03 & $8.16+$ & .07 \\
\hline
\end{tabular}

All yields are annual internally compounded rates of return. Numbers following the + signs are standard errors. 
component of spot rates and $\overline{\mathrm{IRE}}_{3}$ and $\overline{\mathrm{IRE}}_{4}$ on a 100 basis point change in the inflation rate. For a change in the nominal spot rate which is partly due to real effects and partly due to inflation, a weighted average of the real and inflationary $\overline{I R E}$ 's would be calculated. ${ }^{18}$

The second distinction in $\overline{\text { IRE }}$ estimates involves the separation of income and wealth effects in the equation for the proportional change in net worth (equation (18)). The wealth effect results from the existing cash flows being priced by a new discount factor. The income effect involves the pricing of the changes in future cash flows resulting from changes in future spot rates. It has been suggested that in an efficient market and with all the components of risk adjustment correctly specified and measured, there would be no income effect. ${ }^{19} \quad \overline{I R E}_{1}$ and $\overline{I R E}_{3}$ are estimates of the percentage change in net worth including the full income effect, while $\overline{\operatorname{IRE}}_{2}$ and $\overline{\operatorname{IRE}}_{4}$ only include the wealth effect. Thus, since the income effect is positive, $\overline{\operatorname{IRE}}_{1}$ and $\overline{\operatorname{IRE}}_{3}$ are lower limits on the estimates of the percentage change in net worth, and $\overline{\mathrm{IRE}}_{2}$ and $\overline{\mathrm{IRE}}_{4}$ are upper limits on these estimates.

An examination of Tables $13-15$ shows that the estimates of the sensitivity of bank net worth to spot rate changes are all negative. Banks of the sort modeled in this study are made worse off by interest rate increases. However, the magnitude of the estimated net worth losses is quite small especially in comparison with the elasticity estimates for bonds reported in Table 3. For example, according to Table 3 a 100 basis

18 We have placed the bar over the symbol for the percentage change in bank net worth per 100 basis point change in interest rates to distinguish this concept from the interest-rate elasticities for bonds which were expressed as percentage changes in value for a $1 \%$ change in one plus the spot interest rate.

${ }^{19}$ This point was first brought to our attention by William Sharpe. 
Table 13. Market Values and Interest-Rate Elasticities for January 1973

\begin{tabular}{|c|c|c|c|c|c|}
\hline \multirow[b]{2}{*}{$\begin{array}{c}\text { Book Capital } \\
\text { Ratio } \\
\end{array}$} & \multirow{2}{*}{$\begin{array}{l}\text { Estimated } \\
\text { Market Value of } \\
\text { Bank Net Worth }\end{array}$} & & \multicolumn{2}{|c|}{ IRE Estimates } & - \\
\hline & & $\overline{\mathrm{IRE}_{1}}$ & $\overline{\mathrm{IRE}}_{2}$ & $\overline{\mathrm{IRE}}_{3}$ & $\overline{\mathrm{IRE}}_{4}$ \\
\hline 30 & 447.9 & -.40 & -.44 & -.38 & -.41 \\
\hline 20 & 468.2 & -.40 & -.44 & -.38 & -.42 \\
\hline 10 & 528.9 & -.40 & -.45 & -.40 & -.44 \\
\hline 2 & 1014.8 & -.40 & -.47 & -.44 & -.50 \\
\hline
\end{tabular}

$\overline{\mathrm{IRE}}_{1}\left(\overline{\mathrm{IRE}}_{3}\right)$ is the percentage change in bank net worth for a 100 basis point change in the real spot rate (one-month inflation rate) assuming both an income and a wealth effect.

$\overline{\mathrm{IRE}}_{2}\left(\overline{\mathrm{IRE}}_{4}\right)$ is the percentage change in bank net worth for a 100 basis point change in the real spot rate (one-month inflation rate) assuming there is no income effect.

Market values are in units of $\$ 1$ million. 
Table 14. Market Values and Interest-Rate Elasticities for January 1974

\begin{tabular}{|c|c|c|c|c|c|}
\hline $\begin{array}{c}\text { Book Capital } \\
\text { Ratio } \\
\end{array}$ & $\begin{array}{c}\text { Estimated } \\
\text { Market Value of } \\
\text { Bank Net Worth }\end{array}$ & $\overline{\mathrm{IRE}_{1}}$ & $\begin{array}{l}\operatorname{IRE} \mathrm{E} \\
\overline{\operatorname{IRE}}_{2}\end{array}$ & $\overline{\mathrm{IRE}}_{3}$ & $\overline{\overline{\operatorname{IRE}}_{4}}$ \\
\hline 30 & 464.4 & -.23 & -.26 & -.22 & -.25 \\
\hline 20 & 489.5 & -.23 & -.26 & -.22 & -.25 \\
\hline 10 & 564.9 & -.23 & -.27 & -.23 & -.26 \\
\hline 2 & 1168.0 & -.23 & -.28 & -.24 & -.28 \\
\hline
\end{tabular}

$\overline{\operatorname{IRE}}_{1}\left(\overline{\operatorname{IRE}}_{3}\right)$ is the percentage change in bank net worth for a 100 basis point change in the real spot rate (one-month inflation rate) assuming both an income and a wealth effect.

$\overline{\operatorname{IRE}}_{2}\left(\overline{\operatorname{IRE}}_{4}\right)$ is the percentage change in bank net worth for a 100 basis point change in the real spot rate (one-month inflation rate) assuming there is no income effect.

Market values are in units of $\$ 1$ million. 
Table 15. Market Values and Interest-Rate Elasticities for May 1975

\begin{tabular}{|c|c|c|c|c|c|}
\hline \multirow[b]{2}{*}{$\begin{array}{c}\text { Book Capital } \\
\text { Ratio }\end{array}$} & \multirow{2}{*}{$\begin{array}{c}\text { Estimated } \\
\text { Market Value of } \\
\text { Bank Net Worth }\end{array}$} & & \multicolumn{2}{|c|}{ IRE Estimates } & - \\
\hline & & $\overline{\operatorname{IRE}}_{1}$ & $\overline{\mathrm{IRE}}_{2}$ & $\overline{\mathrm{IRE}}_{3}$ & $\overline{\operatorname{IRE}}_{4}$ \\
\hline 30 & 516.9 & -.29 & -.39 & -.29 & -.37 \\
\hline 20 & 546.1 & -.29 & -.39 & -.29 & -.37 \\
\hline 10 & 633.7 & -.30 & -.40 & -.31 & -.39 \\
\hline 2 & 1134.8 & -.32 & -.45 & -.35 & -.45 \\
\hline
\end{tabular}

$\overline{\operatorname{IRE}}_{1}\left(\overline{\mathrm{IRE}}_{3}\right)$ is the percentage change in bank net worth for a 100 basis point change in the real spot rate (one-month inflation rate) assuming both an income and a wealth effect.

$\overline{\operatorname{IRE}}_{2}\left(\overline{\operatorname{IRE}}_{4}\right)$ is the percentage change in bank net worth for a 100 basis point change in the real spot rate (one-month inflation rate) assuming there is no income effect.

Market values are in units of $\$ 1$ million. 
point increase in the May 1975 spot rate would have resulted in a decrease in the net worth of a $10 \%, 10$ year coupon bond of between 2.3 and $3.4 \%$. From Table 15, we can see that the same spot rate change is estimated (at most) to result in a change in the net worth of the hypothetical bank of less than $0.5 \%$.

Another point of interest from Tables $13-15$ is that the $\overline{\text { IRE }}$ estimates for the bank are rather insensitive to whether the source of the spot rate change is real rates or inflation. Again we can contrast this result with the almost $50 \%$ greater sensitivity to inflation displayed by 10 year bonds in Table 3.

Both the small magnitude of the estimated net worth elasticities for bank net worth and their insensitivity to the source of spot rate changes can be attributed to the model bank's loan mix which is predominantly floating rate loans and short-term notes. Even though loan renewals and loan comitments tend to make the effective maturity of loan portfolios longer than their nominal maturities, the fact that they are largely floating rate loans (or equivalently renegotiable on renewal) and are supported to a significant degree by interest-sensitive borrowed funds means that the hypothetical bank is quite close to being immunized from nominal interest rate changes.

These conclusions should be tempered somewhat by the realization that the market value estimates are biased upward. The major reason for this bias is that the estimated cash flows do not include non-interest expenses for the hypothetical bank. Including non-interest rate expenses would have involved arbitrary allocation of actual expense for the bank to the asset and liability categories which were modeled in the hypothetical bank and this was not attempted. However, it is clear that inclusion of such 
expenses would have reduced the measured income effect (assuming that noninterest cash flows would tend to increase as spot rates increase) and to reduce the market value of the bank's net worth. Both effects would tend to increase the sensitivity of the hypothetical bank's net worth to interest rate changes but perhaps not much beyond the estimates that assume no income effects (i.e., $\overline{\operatorname{IRE}}_{2}$ and $\overline{\operatorname{IRE}}_{4}$ ).

Another notable result of the simulations is the insensitivity of the $\overline{\text { IRE }}$ estimates to the book capital ratio. As we decrease the book capital ratio, equity capital is substituted for purchased funds to support the bank's assets. Since the asset structure is unchanged in the process, this would appear to imply that the absolute values of $\overrightarrow{\text { IRE }}$ should fall as the book capital ratio decreases. This line of reasoning ignores the effects of reducing the amount of interest-sensitive purchased funds. As rates increase, future income flows are reduced due to increases in the rates paid on purchased funds, and as the amount of purchased funds decreases this negative income effect on the $\overline{\text { IRE }}$ estimates is weakened. However, the relative insensitivity of $\overline{\mathrm{IRE}}_{2}$ and $\overline{\operatorname{IRE}}_{4}$ (i.e., the estimates that do not include income effects) to changes in the assumed book capital ratio suggest that this income effect is not important; on the whole purchased funds are being purchased at market prices. On the other hand, rate increases result in decreases in the market value of outstanding liabilities and, of course, decreases in the market value of purchased funds result in increases in the bank's net worth. As purchased funds become a less important source of funds for the bank, this positive wealth effect on $\overline{\text { IRE }}$ as the book capital ratio decreases completely offsets the associated increase in the market value of the equity. 
The level and structure of interest rates is seen to have some effect on $\overline{\text { IRE }}$ estimates. For the two upward sloping term structures (January 1973 and May 1975), the difference in the $\overline{\text { IRE }}$ estimates is small especially when we just consider wealth effects. However, the $\overline{\text { IRE }}$ estimates for the humped curve of January 1974 are consistently smaller than their counterparts for the other two term structures. This suggests that the level of interest rate risk for banks of the sort described here is smaller when interest rates are anticipated to be at or near a peak than it is when rates are expected to rise. Given the importance of wealth effects in determining the $\overline{\text { IRE }}$ estimates, this is a reasonable result.

\section{Conclusions}

In this study we have demonstrated a method for estimating the market value of net worth and the sensitivity of that net worth to changes in interest rates for a hypothetical wholesale bank. The major conclusion reached from our simulations is that interest rate risk is not a very significant proposition for a bank similar to the bank in our model (or for the loan portfolio of a more complex bank with a similar loan mix and where it is assumed that loans are supported by demand deposits and purchased funds). Decreasing the ratio of total assets to book capital was shown to have little effect on the interest rate sensitivity in percentage terms though of course the smaller asset to capital ratio implies a larger buffer for depositors in absolute terms.

While the results of this study suggest that there is little need for regulatory attention to interest rate risk for loan portfolios of the sort modeled here, it does not follow that the approach discussed here is useless in other aspects of risk evaluation for banks. The results in Table 3 suggest that the interest rate risk for municipal bond portfolios may well 
be an important source of risk for banks. Application of generalized duration concepts to bond portfolios is a relatively simple proposition and could readily be incorporated into the examination process. Furthermore, except in money center banks, loan portfolios may be less well immunized from interest rate changes than was true for the simplified bank examined here.

This is clearly the case for real estate portfolios. A companion study to the one reported here was made by Nadauld (1978). He attempted to measure market values of net worth and interest-rate elasticities of net worth for savings and loan associations. The results in the Nadauld study suggest that net worth losses from $36 \%$ to $71 \%$ (depending on the association considered) are feasible for interest rate changes similar to those that have occurred in the past. Clearly, the real estate portfolio of commercial banks is another potential area of application by examiners of the principles discussed in this study. 
References

Conte, S. D. 1965. Elementary Numerical Analysis. New York: McGraw-Hill.

Fair, R. C., and Jaffee, D. M. 1972. "Methods of Estimation for Markets in Disequilibrium." Econometrica (May): 497-514.

Fama, E. F. 1975. "Short-Term Interest Rates as Predictors of Inflation." American Economic Review (June): 269-282.

Goldfeld, S. M. 1966. Commercial Bank Behavior and Economic Activity. Amsterdam: North-Holland Publishing Co.

Goldfeld, S. M., and Quandt, R. E. 1975. "Estimation in a Disequilibrium Market and the Value of Information." Journal of Econometrics

(September): 325-348.

Hicks, J. R. 1939. Value and Capital. London: Oxford Press.

Hildreth, G., and Lu, J. Y. 1960. "Demand Relations with Autocorrelated Disturbances." Technical Bulletin 276 (November). Michigan State University Agricultural Experiment Station.

Hodges, S. 1975. "Some Thoughts on the Pricing of Default Free Bonds." Unpublished Working Paper, University of California, Berkeley (January).

Jaffee, D. M. 1971. Credit Rationing and the Commercial Loan Market. New York: John Wiley and Sons, Inc.

Kane, E. J. 1975. "Direct Cross-Section Tests of Alternative TermStructure Theories." Unpublished Working Paper (October).

Lanstein, R. and Sharpe, W. F., "Duration and Security Risk." Research Paper \#451, Graduate School of Business, Stanford University (May).

Macaulay, F. R. 1938. Some Theoretical Problems Suggested by the Movements of Interest Rates, Bond Yields, and Stock Prices in the United States Since 1856. National Bureau of Economic Research. New York: Columbia University Press.

McCulloch, J. H. 1971. "Measuring the Term Structure of Interest Rates." Journal of Business (January): 19-31.

- 1975a. "An Estimate of the Liquidity Premium." Journal of Political Economy (January-February): 95-119.

(June): $\begin{array}{r}1975 \mathrm{~b} . \\ 811-830 .\end{array}$ 
Morrison, J. B. 1977. Interest Rate Risk in Commercial Banking: Some Implications for Capital Adequacy. Unpublished dissertation, University of California, Berkeley (May).

Nadauld, S. J. 1978. The Interest Rate Elasticity of Networth in Savings Institutions. Unpublished dissertation, University of California, Berkeley (May).

Nelson, C. R., and Schwert, W. C. 1976. "On Testing the Hypothesis That the Real Rate of Interest is Constant." Unpublished Working Paper (April).

Rubinstein, M. E. 1975. "The Valuation of Uncertain Income Streams and the Pricing of Options." Research Program in Finance, Working Paper No. 37. Berkeley: Institute of Business and Economic Research, University of California (August).

Samuelson, P. A. 1945. "The Effects of Interest Rate Increases on the Banking System." American Economic Review (March): 16-41.

Vasicek, O. A. 1976. "The Term Structure of Interest Rates." Unpublished Working Paper (July).

Yawitz, J. W., Hempel, G. H., and Marshall, W. J. 1975. "Average Maturity as a Risk Proxy in Investment Decisions." Journal of Finance (May): 325-333. 